\title{
Competencies based innovative learning solutions for co-development of climate services in West Africa
}

\author{
Vieri Tarchiani ${ }^{1}$, Elena Rapisardi ${ }^{1}$, Patrick Parrish ${ }^{2}$, Edmondo Di Giuseppe $^{1}$, Maurizio Bacci ${ }^{1}$, \\ Marina Baldi ${ }^{1}$, and Massimiliano Pasqui ${ }^{1}$ \\ ${ }^{1}$ Istituto per la BioEconomia, Consiglio Nazionale delle Ricerche, Firenze, 50019, Italy \\ ${ }^{2}$ Training Activities Division, Education and Training Office, \\ World Meteorological Organization, Geneva, 1211, Switzerland \\ Correspondence: Vieri Tarchiani (vieri.tarchiani@ibe.cnr.it)
}

Received: 12 February 2020 - Accepted: 14 May 2020 - Published: 9 June 2020

\begin{abstract}
In developing countries, and particularly in West Africa, the role of Climate Services (CS) for sustainable development is growing thanks to wide spreading collaboration among European institutions, including National Meteorological and Hydrological Services (NMHS) research centers, universities, and homologue local institutions. Operationally, the implementation of CSs in developing countries is mainly pivoted on NMHS, which, according to the World Meteorological Organization (WMO), are dramatically affected by unmet learning demand.

The global scale of learning needs for co-development of CSs calls for innovative solutions and a range of flexible modalities to reach learners in a variety of ways, and for sharing resources and successful strategies within the global education and training community. In order to harmonize expected learning outcomes, WMO defined a competency framework (CF) for CSs to be used in the implementation of training initiatives and knowledge sharing tools.

This paper presents the strategic and methodological approach adopted in the implementation of the TOPaCS, a new knowledge-based distance learning initiative, aiming to provide a flexible learning environment within the CSs CF of WMO ensuring coherence with other WMO education initiatives (Global Campus, other RTCs, etc.).

The methodological approach adopted is based on the competency-based approach to training, where competencies are composed by elements of knowledge and skill. TOPaCS integrates the WMO CF for CSs into a taxonomy co-designed with stakeholders at different levels, and allows the definition of learning paths, which are a further interactive opportunity for co-development of CSs within the TOPaCS learning ecosystem. Indeed, the approach aims also to guide further instructional strategies and assessments and becomes a starting point to build a common language enabling a better cooperation and exchange between the different CSs training initiatives.
\end{abstract}

\section{Introduction}

Since the establishment by the World Meteorological Organization (WMO) of the Global Framework for Climate Services (CSs) in 2011 (WMO, 2011), many initiatives have been implemented to support developing and emerging countries, particularly vulnerable to meteorological and hydrological extreme events, in the establishment of weather and CSs (Vincent et al., 2018). In Europe, National Meteorological and Hydrological Services (NMHS) engaged, since the
World Climate Conference-3 in 2009, in establishing CSs (Brasseur and Gallardo, 2016), and the European Commission took a leading role on CSs in Europe through a research and innovation roadmap (Street, 2016) completed by relevant investments with the Horizon-2020 program and the EU Copernicus Program.

In developing countries, and particularly in West Africa (WA), the role of CSs for sustainable development is growing but with a slower rate compared to other regions 
due to the lack of strong national institutions (Brasseur and Gallardo, 2016). On the other hand, funding agencies and development organizations are sustaining this effort (Vaughan et al., 2019), perceiving CSs as a powerful tool for sustainable development including climate change adaptation and disaster risk reduction (Street et al., 2019). Therefore, the collaboration among European and US institutions, including NMHS, research centers, universities, and homologue institutions in developing countries is widely spreading (Brasseur and Gallardo, 2016; Vaughan et al., 2019).

Agriculture is the first sector in WA where CSs have been applied and the impact demonstrated by some ex post studies (Lo and Dieng, 2015; Anouga and Gordon, 2016; Tarchiani et al., 2017, 2018; Ouedraogo et al., 2018). In a general perspective, climate information is a valuable resource for planning and decision-making but the challenge according to Street (2016) is "to transform climate-related data into customized products, to advise on best practices, and to develop and evaluate solutions that may be of use for society".

The operational implementation of CSs is a two-fold challenge: on one side developing approaches/methodologies to transform meteo-climatic information into useful "information products" tailored on users' needs (Vincent et al., 2018) on the other hand building local capacities through training initiatives and knowledge-sharing tools allowing key users to hone their skills and competences (Nkiaka et al., 2019).

The two aspects have been addressed by Vincent et al. (2018) with the theory of co-production of CSs. Indeed, even if the co-production is not a prerequisite for a CS, it is increasingly promoted in order to strengthen the partnership between producers and users (Vaughan and Dessai, 2014). While state institutions such as NMHS are more likely to use "top-down" approaches, research and development organizations are sustaining the co-production integrating also the bottom-up approach bridging the gap between producers and users (Brasseur and Gallardo, 2016). On the other hand, co-production implies an adaptation of the work-flow "moving from supply-driven to demand-driven models", increased flexibility and adaptive programming "to incorporate learning into activities in real time" (Vincent et al., 2018).

Operationally, the implementation of CSs in developing countries is facing large capacity gaps. According to the Status of Human Resources in NMHS (WMO, 2017), unmet learning demand impacts more than $20 \%$ of the global NMHS workforce. In least developed countries (LDC) the situation is even worse because retirements (30 of 81 LDC reported that more than $30 \%$ of their staff were due to retire in the next five years). In Africa, $93 \%$ of climatologists need capacity development and CSs is the 3rd priority over 18 topic areas.

In the frame of CSs, capacity development, beside technical aspects of services production, is also required to "support informed engagement with the intended and potential users to support co-design, co-delivery and co-evaluation, and to provide a better understanding of what is available and how it can be used" (Street et al., 2019).

The global scale of learning needs for CSs calls for innovative solutions and a range of flexible modalities to reach learners in a variety of ways, and for sharing resources and successful strategies within the global education and training community. A new paradigm of education is therefore needed, based on object-oriented instructional design, ensuring fine-grained accessibility and improved reusability (Parrish, 2004) and on the Design-based Research, iteratively improving a training design through trials (Barab, 2006). This is particularly appropriate for CSs and particularly under the co-development perspective, where the training intervention needs a progressive improvement based on results' evaluation and newly recognized needs (Tarchiani et al., 2019). Moreover, classical vocational training approaches result in high costs for face-to-face short and medium-term courses. Therefore, WMO and other partners are increasingly investing in blended solutions or pure distance learning options.

In order to harmonize expected learning outcomes, WMO defined a Competency Framework (CF) for Provision of CSs, which can be used to implement training initiatives and knowledge sharing tools and to allow key users to hone their skills and competencies (WMO, 2019a).

Within the WMO, the Education and Training Programme relies on the network of Regional Training Centers (RTC) in helping member countries develop operational CSs. The RTC in Italy, in agreement with WMO, since 2016 engaged in CSs capacity building for NMHS in the 17 member states of CILSS/ECOWAS in WA. The RTC in Italy is hosted and managed by the Institute of BioEconomy of the Italian National Research Council (IBE-CNR) in Florence - Italy, having been designated as RTC by the WMO Executive Council in 1997 (WMO, 1997).

WMO RTC Italy recent training courses on CSs for WA highlighted the need for users to continually update and improve their knowledge, skills, and competencies. This paper is not conceived as a classical research paper but it aims to present the strategic and methodological approach adopted in the implementation of a new knowledge-based distance learning initiative originated from the recommendation of the Directors of Meteorological Services of 17 CILSS/ECOWAS Countries at the International Conference on CSs for WA in Rome, Italy, early 2019 (WMO, 2019b). The initiative addresses the need for increased sharing of training resources and approaches, increasing the access to learning opportunities in a lifelong perspective, and developing common accreditation, certification, evaluation and assessment systems on the topic of CSs.

\section{The approach}

The new initiative, called TOPaCS (Training Operational Package for $\mathrm{CSs}$ ) aims to contribute to the operational imple- 
mentation of the WMO Global Campus, encouraging multilateral collaboration among RTCs and other training institutions and by providing an open platform for sharing training contents, tools and learning technologies that all providers and users of CSs can use.

The methodological approach adopted is based on the competency-based approach to training (Dubois and Rothwell, 2004), where competencies are composed by knowledge and skills, according to the European Qualifications Framework for Lifelong Learning (EC, 2008). The WMO CSs CF, that has been co-designed with stakeholders at different levels, represents the competence level of the TOPaCS taxonomy. In order to improve the learning experiences and to address personalized learning, TOPaCS proposes asynchronous short courses and learning materials that trainers can use autonomously having full control over their learning process (Brady, 2004). Moreover, learning paths could be set up to offer further customizable eLearning opportunity for co-development of CSs within the TOPaCS learning ecosystem. Indeed, the approach aims also to guide further instructional strategies and assessments and become a starting point to build a shared approach enabling a better cooperation and exchange between the different CSs training initiatives.

\section{Solutions}

The technical specification of TOPaCS have been defined starting from the need of:

- tracking the learning progress;

- certifying through badges the knowledge and skills achieved;

- linking with WMO CF for CS providers;

- ensuring open and free access to eLearning resources.

The TOPaCS information architecture follows the classical structure of Moodle deployment. Each course is structured with a course overview with: (a) a short presentation video, (b) detailed information on skills, knowledge and WMO Competencies related to the course, (c) badges functionality. As some courses are pre-requisite to others, the enrollment to the courses that requires the prerequisite course is based on badge enrollment: when the trainee acquires the pre-requisite course badge he can enroll in other courses.

An in-depth explanation of the TOPaCS approach, the WMO CSs CF and Badges are in a specific section of the deployment (labelled "About TOPaCS") at https://topacs.ibe. cnr.it/ (last access: 8 June 2020).

TOPaCS is developed with Moodle (version 3.8), where some plugins and functions are enabled to manage competencies, enrolment types, badges, such as Moodle competency framework functionality.
In order to ensure open and free access to eLearning resources, TOPaCS Moodle deployment provides, beside the classical manual accounts created by an administrator, an OAuth 2.0 service. The OAuth 2.0 is a protocol that allows the users to grant limited access to their resources on one site to another site, without having to expose their credentials. OAuth (and its subsequent implementation OAuth 2.0) is an open standard for access delegation, commonly used as a way for Internet users to grant websites or applications access to their information on other websites but without giving them the passwords. OAuth allows the creation of an authentication system (via HTTPS API) which authorizes our Moodle deployment to communicate securely with the ID providers that give authorization to register accounts (a dedicated account for Google, Microsoft, Facebook, etc.). TOPaCS is actually working with Google OAuth 2.0 but the authentication can be easily implemented with other services such as Microsoft, Facebook, Nextcloud and GitHub services.

At present TOPaCS includes 11 Courses on different topics related to CSs for a total of 191 lessons, and it is open to host other learning resources provided by other centers and initiatives. Each lesson is composed by a variable combination of video lessons, podcasts, text lessons, external materials, webinars and other learning resources. Each course has a final quiz comprised of up to 10 questions (True/False; Multiple choices; Calculated; Select Missing Word).

After completion of each training course with the minimum grade, the trainee receives the course badge where competencies, knowledge, and skills on which he/she has been trained are displayed in the description. Badges are displayed in the user backpack of Moodle and can be linked with Open badges (badgr.io) to track the learning progress and certify the knowledge and skills achieved also outside the Moodle environment. The Badgr.io platform was chosen, not only because it is widely used, but also as it can integrate badges from Moodle and other platforms. Once the user creates an account on Badgr.io, he/she can upload Moodle badge directly from the Moodle user profile to the Badgrio Backpack where to store all the Open Badges earned with Moodle as well as with other platforms or training courses.

One of the main challenges was to find a coherent approach to match the different ways that competencies are defined in educational and working environments and transpose into the Moodle CF. In education environment, competency is a general statement that describes the desired knowledge, skills and behaviors of a student completing a course. Competencies describe the level of understanding or proficiency of a learner in certain subject-related skills. In the working environment, competencies commonly define the applied skills and knowledge that enable people to successfully perform in professional contexts. Moodle Competencies Framework is a hierarchical taxonomy, i.e. a structure in which the taxons are organized hierarchically. Each taxon could have one parent taxon and unlimited number of child taxa. 
WMO Competencies Framework for CSs Providers is structured in levels - Performance Criteria and Outcomes but is not fully hierarchical due to overlapping background knowledge and skills and performance criteria across some competencies.

In order to match the two approaches, TOPaCs uses the Hierarchical Taxonomy of Moodle where the first two levels are provided by the WMO CF for CSs Providers and a third level has been added for "Knowledge \& Skills".

Because the training does not necessarily indicate job proficiency, the Competency Scale has been modified from the original value of "proficient" into "trained" by modifying the label in the Moodle Language Pack.

Competencies are listed for each course and linked to a specific activity completion in the course (e.g. Quiz, Lessons). When the user completes the activity, the competency is marked as completed and the system displays the phrase "You are trained in...".

\section{Conclusions}

TOPaCS has just been published and we are not yet able to provide statistics on its use and impacts on the strengthening of users' capacities toward the co-development of CS. Indeed, the paper doesn't aim to present "Results", but only the rationale and the approach. TOPaCS should be seen as a starting point, toward the creation of a community of users, with a common and flexible language to foster better cooperation and exchange between the different CSs training initiatives. The whole effort aims to improve the sustainability of learning and training initiatives. The high costs of formal training demand adoption of more flexible and integrated approaches and to optimize the resources and the offers of training. In this perspective, the consolidation of learning resources for CS under WMO guidance in a coherent CF is an important step forward.

We cannot hide or ignore the intrinsic limitations of the experience. Some are embedded in any training initiative such as the motivation of users. Others are specific to the adopted tools, such as the limited usability of any open source platform, like Moodle, or even for the learning supports, such as for the materials not originally created for distance learning that demand relevant effort to be adapted. Nevertheless, according to the learning by doing principle and the "Designbased Research" (Barab, 2006), the training design is iteratively improved through trials, therefore TOPaCS is progressively evolving as far as new courses are added and feedbacks received from users.

The prospects are exciting, also thanks to the enthusiastic response of the training community within WMO for Region I Africa when the TOPaCS was presented at the RA-I WMO Global Campus Meeting in Cairo in November 2019. The idea is to conceive, test and document a common strategy among RTCs and other Global campus partners to track learning progress in competency-based training. The objective is not to assess competencies, which can be assessed only on-site considering the behavior and the specific characteristics of the country and the institution, but to propose a simple option that maximizes effectiveness and minimizes costs, for tracking the achieved learning goals of a training course. In this perspective, the use of Open Badges with Badgr.io Backpack allows the transparency and sharing of individual learning achievements, keeping tracks of the training curriculum of each user. Therefore, the model should allow:

- trainees to demonstrate their learning achievements related to WMO CFs;

- training centers to check the curricula of trainees and improve selection processes as well as better target training offer linking courses directly to WMO CFs;

- WMO to track the progress in capacity building in relation to CFs.

The RTC in Italy is testing the first prototype of TOPaCS using Moodle CF functionality, WMO CF for CSs Providers and badgr.io as Open Badges provider. Feedbacks of this first test will be the building block for:

- harmonizing a Moodle CF with the WMO CF (not only for CSs);

- choice of a common Open badge system;

- detail a proposal on the best possible options for harmonizing RTCs and other training providers approaches to track learning in knowledge-based training with practical recommendations and a manual on how to apply it operationally.

The TOPaCS provides also indirect benefits and opens new solutions to overcome some common problems in training. For example, the Distance Learning courses can be used in the selection process for workshops and open badges can be used as enrollment pre-condition of more specialized courses. A permanent training platform, such as TOPaCS, opens to a wide range of training initiatives focused on Climate and Climate Services, from specific micro-learning to customizable learning paths. Moreover, a customizable and open tool, where the best learning content from diverse institutes and organizations can be collected, could contribute to a response to the increasing need for innovating knowledge, skills and competencies in the co-development of CSs.

Data availability. Data are publicly accessible on request to the authors and according with the GDPR. TOPaCS is available at https: //topacs.ibe.cnr.it/ (last access: 8 June 2020) (Tarchiani et al., 2020).

Author contributions. VT coordinated the PACC training programme, MBal and PP supervised the training activities, MP, 
MBac and EDG designed the scientific content and coordinated the realization of the training courses with the support of ER. ER implemented the distance learning structure and supervised the content production and the population with learning content. VT prepared the manuscript with contributions from co-authors.

Competing interests. The authors declare that they have no conflict of interest.

Special issue statement. This article is part of the special issue "19th EMS Annual Meeting: European Conference for Applied Meteorology and Climatology 2019”. It is a result of the EMS Annual Meeting: European Conference for Applied Meteorology and Climatology 2019, Lyngby, Denmark, 9-13 September 2019.

Acknowledgements. The authors thank Roberto Colaminè (MAECI) and Yinka Adebayo (WMO) for trusting in the project and always encouraging our work. They are grateful to Guido Righini and Marco Simonetti of the Institute of Crystallography - CNR, for the essential contribution in setting up and managing the Moodle platform. This study was developed in the framework of the training project Projet d'Adaptation au Changement Climatique et Réduction des Risques de Catastrophe funded by the Italian Ministry for Foreign Affairs and International Cooperation.

The authors are grateful to the reviewers for their comments and for helping to improve the manuscript.

Review statement. This paper was edited by Stefanie Gubler and reviewed by Jorge Tamayo and one anonymous referee.

\section{References}

Anuga, S. W. and Gordon, C.: Adoption of climate-smart weather practices among smallholder food crop farmers in the Techiman municipal: Implication for crop yield, Res. J. Agric. Environ. Manage., 5, 279-286, 2016.

Barab, S.: Design-based research, in: The Cambridge handbook of the learning sciences, edited by: Sawyer, R. K., Cambridge University Press, Cambridge, UK, 153-170, https://doi.org/10.1017/CBO9780511816833, 2006.

Brady, L.: Towards optimal student engagement in teacher education, Aust. J. Teach. Educ., 29, 24-33, https://doi.org/10.14221/ajte.2004v29n2.3, 2004.

Brasseur, G. P. and Gallardo, L.: Climate Services: Lessons learned and future prospects, Earth's Future, 4, 79-89, https://doi.org/10.1002/2015EF000338, 2016.

Dubois, D. and Rothwell, W. J.: Competency-based or a traditional approach to training, Train. Dev., 58, 46-57, 2004.

EC - European Commission: European Qualifications Framework for Lifelong Learning, European Commission: Luxembourg, $15 \mathrm{pp}$., available at: http://ecompetences.eu/wp-content/ uploads/2013/11/EQF_broch_2008_en.pdf (last access: 13 January 2020), 2008.
Lo, M. and Dieng, M.: Impact assessment of communicating seasonal climate forecasts in Kaffrine, Diourbel, Thies and Fatick (Niakar) regions in Senegal, CCAFS, Copenhagen, Denmark, 70 pp., available at: https://cgspace.cgiar.org/bitstream/handle/ 10568/67171/ImpactassessmentScalingupCISinSenegal.pdf (last access: 24 November 2019), 2015.

Nkiaka, E., Taylor, A., Dougill, A. J., Antwi-Agyei, P., Fournier, N., Bosire E. N., Konte, O., Lawal, K. A., Mutai, B., Mwangi, E., Ticehurst, H., Toure, A., and Warnaars, T.: Identifying user needs for weather and climate services to enhance resilience to climate shocks in sub-Saharan Africa, Environ. Res. Lett., 14, 123003, https://doi.org/10.1088/1748-9326/ab4dfe, 2019.

Ouedraogo, I., Diouf, N. S., Ouédraogo, M., Ndiaye, O., and Zougmoré, R.: Closing the gap between climate information producers and users: Assessment of needs and uptake in Senegal, Climate, 6, 13-29, https://doi.org/10.3390/cli6010013, 2018.

Parrish, P. E.: The trouble with learning objects, Educ. Technol. Res. Dev., 52, 49-67, https://doi.org/10.1007/BF02504772, 2004.

Street, R. B.: Towards a leading role on climate services in Europe: A research and innovation roadmap, Clim. Serv., 1, 2-5, https://doi.org/10.1016/j.cliser.2015.12.001, 2016.

Street, R. B., Buontempo, C., Mysiak, J., Karali, E., Pulquério, M., Murray, V., and Swart, R.: How could climate services support disaster risk reduction in the 21 st century, Int. J. Disast. Risk Reduct., 34, 28-33, https://doi.org/10.1016/j.ijdrr.2018.12.001, 2019.

Tarchiani, V., Rossi, F., Camacho, J., Stefanski, R., Mian, K., Pokperlaar, D., Coulibaly, H., and Sitta Adamou, A.: Smallholder Farmers Facing Climate Change in West Africa: DecisionMaking between Innovation and Tradition, J. Innov. Econ. Manage., 24, 151-176, https://doi.org/10.3917/jie.pr1.0013, 2017.

Tarchiani, V., Camacho, J., Coulibaly, H., Rossi, F., and Stefanski, R.: Agrometeorological services for smallholder farmers in West Africa, Adv. Sci. Res., 15, 15-20, https://doi.org/10.5194/asr-1515-2018, 2018.

Tarchiani, V., Pasqui, M., Parrish, P., Rapisardi, E., Di Giuseppe, E., and Baldi, M.: Learning and teaching about seasonal climate forecasts: a Mediterranean educational experience toward operational climate services, Adv. Sci. Res., 15, 257-262, https://doi.org/10.5194/asr-15-257-2019, 2019.

Tarchiani, V., Rapisardi, E., Di Giuseppe, E., Bacci, M., Baldi, M., and Pasqui, M.: Training Operational Package for Climate Services, available at: https://topacs.ibe.cnr.it, last access: 8 June 2020.

Vaughan, C. and Dessai, S.: Climate Services for Society: Origins, Institutional Arrangements, and Design Elements for an Evaluation Framework, WIREs Clim. Change, 5, 587-603, https://doi.org/10.1002/wcc.290, 2014.

Vaughan, C., Hansen, J., Roudier, P., Watkiss, P., and Carr, E.: Evaluating agricultural weather and climate services in Africa: Evidence, methods, and a learning agenda, WIREs Clim. Change, 10, 586-619, https://doi.org/10.1002/wcc.586, 2019.

Vincent, K., Daly, M., Scannell, C., and Leathes, B.: What can Climate Services learn from theory and practice of co-production?, Clim. Serv., 12, 48-58, https://doi.org/10.1016/j.cliser.2018.11.001, 2018.

WMO: Executive Council - Forty-ninth session, Geneva, 1020 June 1997: abridged final report with resolutions (IP), Executive Council Reports, WMO-No. 867, ISBN 92-63-10867- 
6, available at: https://www.wmo.int/e-catalog/detail_en.php? PUB_ID=316\&SORT=N\&q=1997 (last access: 8 June 2020), 1997.

WMO: Climate Knowledge for Action: a Global Framework for Climate Services, WMO, Geneva, Switzerland, available at: https://library.wmo.int/pmb_ged/wmo_1065_en.pdf (last access: 23 November 2019), 2011.

WMO: Status of Human Resources in National Meteorological and Hydrological Services, ETR-21, WMO, Geneva, Switzerland, 75 pp., available at: https://library.wmo.int/doc_num.php? explnum_id=4184 (last access: 23 November 2019), 2017.
WMO: Compendium of WMO Competency Frameworks, WMO Report No. 1209, WMO, Geneva, Switzerland, 119 pp., available at: https://library.wmo.int/doc_num.php?explnum_id= 10075 (last access: 13 January 2020), 2019a.

WMO West Africa Training Activities on Climate Change and Agriculture, available at: https://public.wmo.int/en/media/news/ west-africa-training-activities-climate-change-and-agriculture (last access: 13 January 2020), 2019b. 